W. J.Weber,

N. J. Hess,

R. E. Williford,

H. L. Heinisch, Pacific Northwest

National Laboratory,

Richland, Washington

99352, USA

B. D. Begg,

Australian Nuclear

Science and

Technology

Organisation, Menai,

NSW 2234, Australia

S. D. Conradson Los Alamos National Laboratory, Los

Alamos, New Mexico 89545, USA

R. C. Ewing

University of

Michigan, Ann Arbor,

Michigan 48109, USA

\section{Plutonium Stabilization in Zircon: Effects of Self-Radiation}

Zircon $\left(\mathrm{ZrSiO}_{4}\right)$ is the most thoroughly studied of all candidate ceramic phases for the stabilization of plutonium. ${ }^{1-2}$ Self-radiation damage from $\alpha$-decay of the ${ }^{239} \mathrm{Pu}$, which releases a $5.16 \mathrm{MeV} \alpha$-particle and a $0.086 \mathrm{MeV}^{235} \mathrm{U}$ recoil nucleus, can significantly affect the structure and properties of zircon (e.g., up to $18 \%$ volume expansion). Two types of synthetic Pu-containing zircons, prepared in 1981, have provided an opportunity to characterize in detail the effects of $\mathrm{Pu}$ decay on the structure and properties of zircon and to make unique comparisons to observations of radiation effects in natural zircons. ${ }^{3-4}$ One set of zircon samples contained a mixture of $8.85 \mathrm{wt} . \%{ }^{238} \mathrm{Pu}$ and $1.15 \mathrm{wt} . \%{ }^{239} \mathrm{Pu}$, while the other set of samples contained 10 wt. $\%{ }^{239} \mathrm{Pu}$. In both instances, the $\mathrm{Pu}$ was substituted directly for $\mathrm{Zr}$, giving a $\mathrm{Zr}_{0.92} \mathrm{Pu}_{0.08} \mathrm{SiO}_{4}$ stoichiometry. Initial characterization by $\mathrm{XR}$, found both samples to be single-phase zircons. The zircons containing $8.85 \mathrm{wt} .{ }^{238} \mathrm{Pu}$, with its 87.7 year half-life, provided a means of accelerating the $\alpha$-decay rate (i.e., damage rate) by a factor of $\sim 250$ when compared to the zircons containing $10 \mathrm{wt} . \%{ }^{239} \mathrm{Pu}$. Self-heating in the ${ }^{238} \mathrm{Pu}$-substituted zircon specimens during storage has been minimal, and specimen temperatures have been estimated to be less than $50^{\circ} \mathrm{C}$. The accumulated doses in these samples are $2.8 \times 10^{19}$ and $1.2 \times 10^{17} \alpha$-decays $/ g$ for the ${ }^{238} \mathrm{Pu}$ - and ${ }^{239} \mathrm{Pu}$-substituted zircons, respectively.

Self-radiation from $\mathrm{Pu}$ decay in zircon results in the simultaneous accumulation of point defects and amorphous domains that eventually lead to a completely amorphous state. ${ }^{3}$ The swelling in zircon increases sigmoidally with dose and is well saturated at the highest dose. The saturation swelling increases with decreasing porosity of the synthesized zircon pellets, from $16.6 \%$ swelling for synthetic zircons with $5.5 \%$ porosity to $18.4 \%$ for natural zircons ( $0 \%$ porosity). In all cases, the swelling can be accurately modeled based on the contributions from crystalline and amorphous components. The XAS results at the highest doses confirmed that self-radiation damage had transformed the ${ }^{238} \mathrm{Pu}$-substituted zircon into a fully amorphous state lacking long-range order. ${ }^{5}$ Surprisingly, the $\mathrm{Pu} \mathrm{L}_{\mathrm{III}}$-edge XANES indicated that the $\mathrm{Pu}$ in both zircon samples is trivalent. This was an unexpected result of originally preparing the Pu-substituted zircons under a reducing atmosphere (oxygen-purged flowing argon). Recent computer simulations using energy minimization techniques indicate that the lowest energy configuration occurs for a defect cluster composed of two near-neighbor $\mathrm{Pu}^{3+}$ substitutions on $\mathrm{Zr}^{4+}$ sites and a neighboring charge-compensating oxygen vacancy. ${ }^{6}$

Detailed X-ray absorption spectroscopy and X-ray diffraction methods have characterized the short-range and long-range structures of each zircon type. ${ }^{7}$ The amorphous state of the ${ }^{238} \mathrm{Pu}$-substituted zircon is consistent with the loss of longrange order and edge-sharing relationships between $\mathrm{SiO}_{4}$ and $\mathrm{ZrO}_{8}$ polyhedra. Despite this, a distorted zircon structure and stoichiometry, which consists of $\mathrm{SiO}_{4}$ and $\mathrm{ZrO}_{8}$ polyhedra that have rotated relative to each other, are retained over length scales up to $0.5 \mathrm{~nm}$. The recrystallization of the amorphous ${ }^{238} \mathrm{Pu}$-substituted zircon could be achieved directly at temperatures as low as $1200^{\circ} \mathrm{C}$ if heated rapidly through the intermediate temperature regime where decomposition to oxides is preferred. The decomposition of amorphous zircon to constituent oxides observed at intermediate temperatures is probably kinetically limited by $\mathrm{Zr}$ diffusion, which has a lower energy barrier than the polyhedral rotation required 
for recrystallization of the zircon structure from the amorphous state. The oxidation of $\mathrm{Pu}^{3+}$ to $\mathrm{Pu}^{4+}$ in the crystalline ${ }^{239} \mathrm{Pu}$-substituted zircon during annealing in air results in a decrease in lattice distortion due to the decrease in ionic radius of $\mathrm{Pu}^{3+}$ to $\mathrm{Pu}^{4+}$ on the $\mathrm{Zr}^{4+}$ site.

Atomic-scale computer simulations have also been used to study defect accumulation and amorphization in zircon containing ${ }^{238} \mathrm{Pu} .{ }^{8} \mathrm{~A}$ kinetic Monte Carlo simulation has been used that includes the stochastic production of defects in displacement cascades, the subsequent diffusion of defects, and the identification of amorphous regions. The displacement cascades in zircon from ${ }^{234} \mathrm{U}$ recoils are generated using a crystalline binary collision model, and the diffusion of the defects is followed as they hop stochastically through the crystal lattice. The simulation results for the amorphous fraction as a function of alpha-decay dose are in excellent agreement with the experimental results. Furthermore, the simulation results indicate that cascade overlap may be the dominant process for amorphization of zircon at $300 \mathrm{~K}$; however, the results also suggest that there is a minor contribution from direct impact amorphization.

\section{References}

1. R. C. Ewing, W. Lutze, and W. J. Weber, J. Materials Research 10, 243-246 (1995).

2. E. B. Anderson, B. E. Burakov, and E. M. Pazukhin, Radiochimica Acta 60, 149-151 (1993).

3. W. J. Weber, J. Materials Research 5, 2687-2697 (1990).

4. T. Murakami, B. C. Chakoumakos, R. C. Ewing, G. R. Lumpkin, and W. J. Weber, Am. Mineralogist 76, 1510-1532 (1991).

5. N. J. Hess, W. J. Weber, and S. D. Conradson, J. Nuclear Materials 254, 175-184 (1998).

6. R. E. Williford, B. D. Begg, W. J. Weber, and N. J. Hess, J. Nuclear Materials (2000), in press.

7. B. D. Begg, N. J. Hess, W. J. Weber, S. D. Conradson, M. J. Schweiger, and R. C. Ewing, J. Nuclear Materials (2000), in press.

8. H.L. Heinisch and W.J. Weber, J. Nuclear Materials (2000), in press. 